\title{
Failure mechanisms and residual capacity of annealed glass/SGP laminated beams at room temperature
}

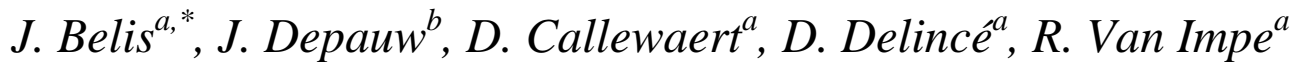 \\ ${ }^{a}$ Laboratory for Research on Structural Models, Ghent University, \\ Technologiepark-Zwijnaarde 904, \\ B-9052 Ghent, Belgium \\ ${ }^{b}$ Jan De Nul n.v., \\ Tragel 60, \\ B-9308 Hofstade-Aalst, Belgium
}

\begin{abstract}
In construction industry, laminated glass is more and more used for transparent loadbearing building components. It is known that the residual load-carrying capacity after glass breakage of glass/PVB (polyvinyl butyral) laminates is relatively poor, mainly due to the limited stiffness and strength of PVB. For that reason, the failure behaviour of laminates composed with a stiffer and stronger interlayer material, called SentryGlas ${ }^{\circledR}$ Plus (SGP), was investigated experimentally. Consequently, $1100 \mathrm{~mm}$ long test samples composed of two annealed float glass layers and one SGP interlayer were subjected to destructive in-plane four-points bending tests. Subsequently, different stages were distinguished during the failure process, corresponding to a different number of broken glass layers. In spite of the relatively good interlayer material properties and in contradiction to what was expected, the observed post-failure safety was poor.
\end{abstract} However, the failure mechanisms observed were significantly different from those of glass/PVB beams: due to a lack of local delamination near the glass fracture zone, tear of the SGP interlayer occurred without preceding large visual interlayer elongations.

\footnotetext{
* Corresponding author. Tel: +329264 5478. Fax: +3292645838.

E-mail address: Jan.Belis@UGent.be (J. Belis)
} 
Keywords: Failure mechanism, Fail safe, Glass ceramics, Fracture, Delamination.

\section{Introduction}

Corresponding to a general trend to create a high level of transparency in building architecture, the number of load-bearing glass applications has been growing significantly during the last decade. For safety reasons, the use of laminated glass, defined as a sandwich structure of alternating glass and adhesive interlayers, is generally accepted for such applications.

By far the most used interlayer material is polyvinyl butyral (PVB), a relatively soft, viscoelastic polymer available as a thin film. However, alternative materials with different properties exist, such as SentryGlas ${ }^{\circledR}$ Plus (SGP), an interlayer originally developed to increase the hurricane resistance of window glazing. To allow a comparison, Table 1 provides some relevant properties of both materials. Due to its relatively high stiffness and strength, SGP is generally believed to be a promising interlayer for structural glass applications as well.

In addition to normal unbroken conditions that are usually considered in design, also the post-breakage behaviour in terms of residual strength, stiffness and load-bearing capacity is of utmost importance to guarantee an acceptable level of safety, especially for structural glass applications. For two-sided supporting conditions, two basic loading cases should be distinguished, namely glass loaded as a plate (i.e. perpendicularly to its surface) and loaded as a beam (i.e. parallel to its surface), as depicted in Fig. 1. 
(a)

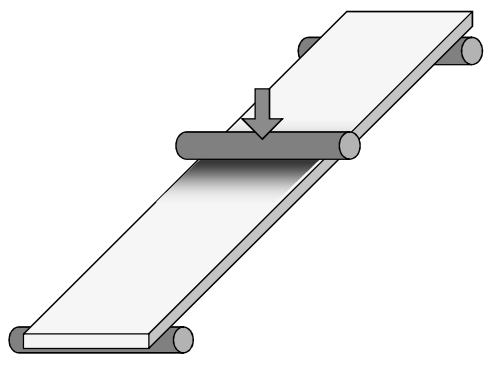

(c)

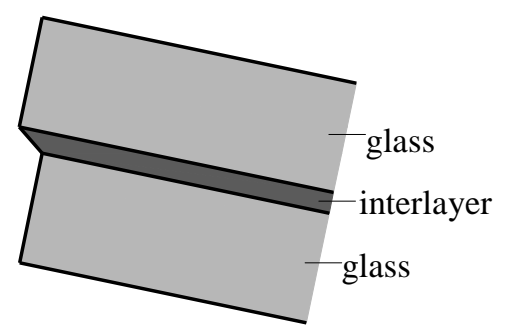

(b)

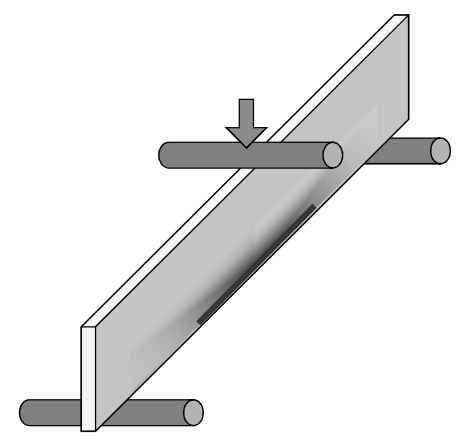

(d)

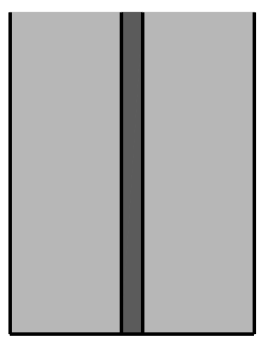

Fig. 1. Basic loading situations for laminated glass: (a) as a plate; (b) as a beam; and (c-d) corresponding longitudinal cross-sections during loading (chamfered edges are neglected in sketches)

For plate applications (Fig. 1 a), amongst others Hooper [1] and Behr et al. [2] have shown that the interlayer plays a major role in the mechanical behaviour (bending) of an unbroken glass laminate, as it is subjected to significant shear stresses (Fig. $1 \mathrm{c}$ ). The post-breakage behaviour of laminated glass plates has been investigated by Bennison et al. [3], Seshadri et al. [4] and Kott [5]. Varying load cases and supporting conditions have been studied, but those works have been restricted to PVB laminates.

Kott [5] defined three stages, each of which corresponds to a certain level of accumulated damage to a laminate consisting of two glass sheets and one PVB interlayer. Stage I represents a situation in which no glass breakage occurred: compressive (C) and tensile ( $\mathrm{T}$ ) bending stress distributions in the glass depend on the shear modulus of the PVB. In the next stage (stage II), one of both glass sheets is 
broken, and tensile bending stresses are taken mainly (or even only) by the remaining unbroken glass layer. Subsequently, stage III corresponds to the situation in which both glass layers are broken in the same cross-section: compressive stresses can still be transferred between the pieces of broken glass, but tensile stresses have to be resisted by the interlayer only. Finally, tear of the interlayer leads to a complete collapse of the laminate.

A schematic representation including compressive (C) and tensile (T) stresses is given in Fig. 2.

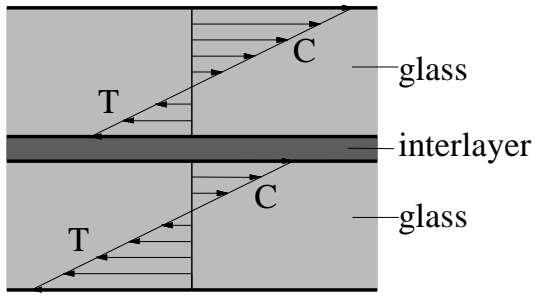

Stage I

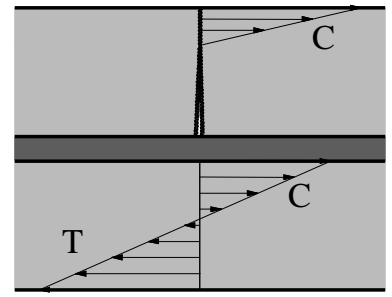

Stage II

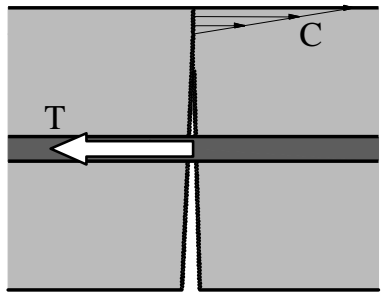

Stage III

Fig. 2. Three stages in the failure process of a laminated plate composed of two glass sheets and one interlayer (in the example shown, the upper sheet broke first, e.g. due to a hard body impact)

Bucak et al. [6] have reported on post-failure tests of glass/SGP laminated plates and more recently Kott's principles have been further developed and applied to annealed laminated glass plates with a SGP interlayer at room temperature by Depauw [7], Belis et al. [8] and Delincé et al. [9].

However, for laminated glass loaded as a beam, little research on post-breakage behaviour has been reported on in literature. Noteworthy in this context is the report published by Hess [10], who destructively tested a series of full-size laminated glass/PVB beams. 
Consequently, taking into account 1) the growing significance of load-bearing glass constructions in contemporary architecture, 2) the high importance of residual capacity after glass breakage, and 3) the lack of information about this topic for glass beams in general and glass/SGP beams in particular, an experimental investigation is presented below on the post-breakage behaviour of laminated glass beams with an SGP interlayer. The main objective of this research is to acquire basic insights in the failure mechanisms and residual capacity of glass/SGP beams at room temperature.

\section{Materials}

Two different kinds of testing materials are presented, the first being SGP samples to study the interlayer behaviour and the second laminated glass specimens to investigate the overall post-breakage behaviour and failure mechanisms.

\subsection{Interlayer}

Initially, 25 T-bone shaped samples have been extracted from a sheet of SGP $\mathrm{S}^{\dagger}$ according to EN ISO 527-2 [11], as illustrated in Fig. 3. The nominal thickness of the sheet was $1.52 \mathrm{~mm}$ and the mean measured thickness was $1.67 \mathrm{~mm}$.

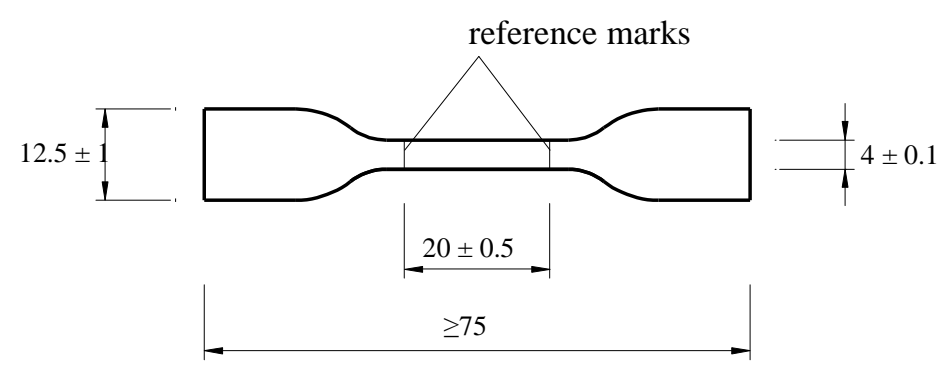

Fig. 3. Basic shape and main sizes of SGP samples used for uniaxial tensile tests [mm] (for more details, see EN ISO 572-2 [11])

\footnotetext{
${ }^{\dagger}$ SGP 2000 was used for the tests. However, at the time of writing a more recent version called SGP 5000 was released [12].
} 


\subsection{Laminates}

In addition, 24 laminated glass pieces with a constant nominal length of $1100 \mathrm{~mm}$ have been tested, divided in three series according to their nominal height (h) $(120 \mathrm{~mm}, 150$ $\mathrm{mm}$ and $200 \mathrm{~mm}$ ). Each test specimen consisted of two glass sheets with an individual nominal thickness (a) of $6 \mathrm{~mm}$, and one SGP 2000 interlayer of $1.52 \mathrm{~mm}$ thick (t) (nominal value). An overview is provided in Table 2.

\section{Experimental methods and results}

The methods and results of the experiments on separate samples of SGP and on the laminates described above, are presented below. As for the laminated beams, analogous failure stages are used to those proposed by Kott [5] for laminated plates: stage I corresponds to an unbroken situation, while stage II and III refer to a situation in which respectively one and two glass sheets are broken.

\subsection{Interlayer}

As the interlayer of a broken glass laminate will obviously be subjected to significant tensile stresses during the failure process, uniaxial tensile tests have been conducted to estimate the basic material response to such type of loading. Even if this type of tests will not be sufficient to build a complete rheological material model, it was expected to provide valuable stress-strain data which correspond to some extent to the loading situation expected during failure of a laminate.

All tensile tests have been executed on an Instron 3369 universal testing machine under controlled temperature $\left(20+/-1^{\circ} \mathrm{C}\right)$ and relative humidity (54\% to $\left.65 \%\right)$ conditions. Using a video extensometer, strains are deduced from optical displacement 
measurements between two reference marks on the samples. Furthermore, loads are directly measured by an integrated load cell.

Taking into account the dependency of the mechanical response of SGP on the load duration [6], five different loading speeds have been adopted from EN ISO 527-1 [13]. An overview of the loading speeds (s) and mean stress-strain data for yielding (y) and ultimate (u) states is presented in Table 3. The corresponding stress-strain curves are depicted in Fig. 4.

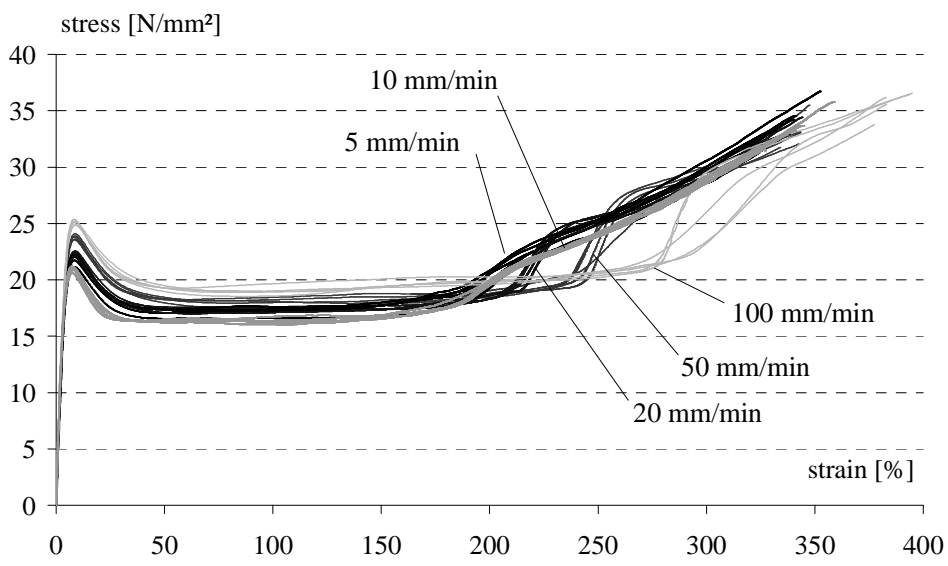

Fig. 4. Stress-strain curves of SGP 2000 samples subjected to uniaxial tensile tests at room temperature

\subsection{Beams}

As no standardised testing procedure exists for glass beams, the supporting and loading conditions of the test setup used were inspired by a standard four-points bending test for glass plates, described in EN 1288-3 [14]. In addition, four lateral supports (provided with Mylar contact layers to prevent friction) were added on both sides to prevent buckling, as depicted in Fig. 5. 


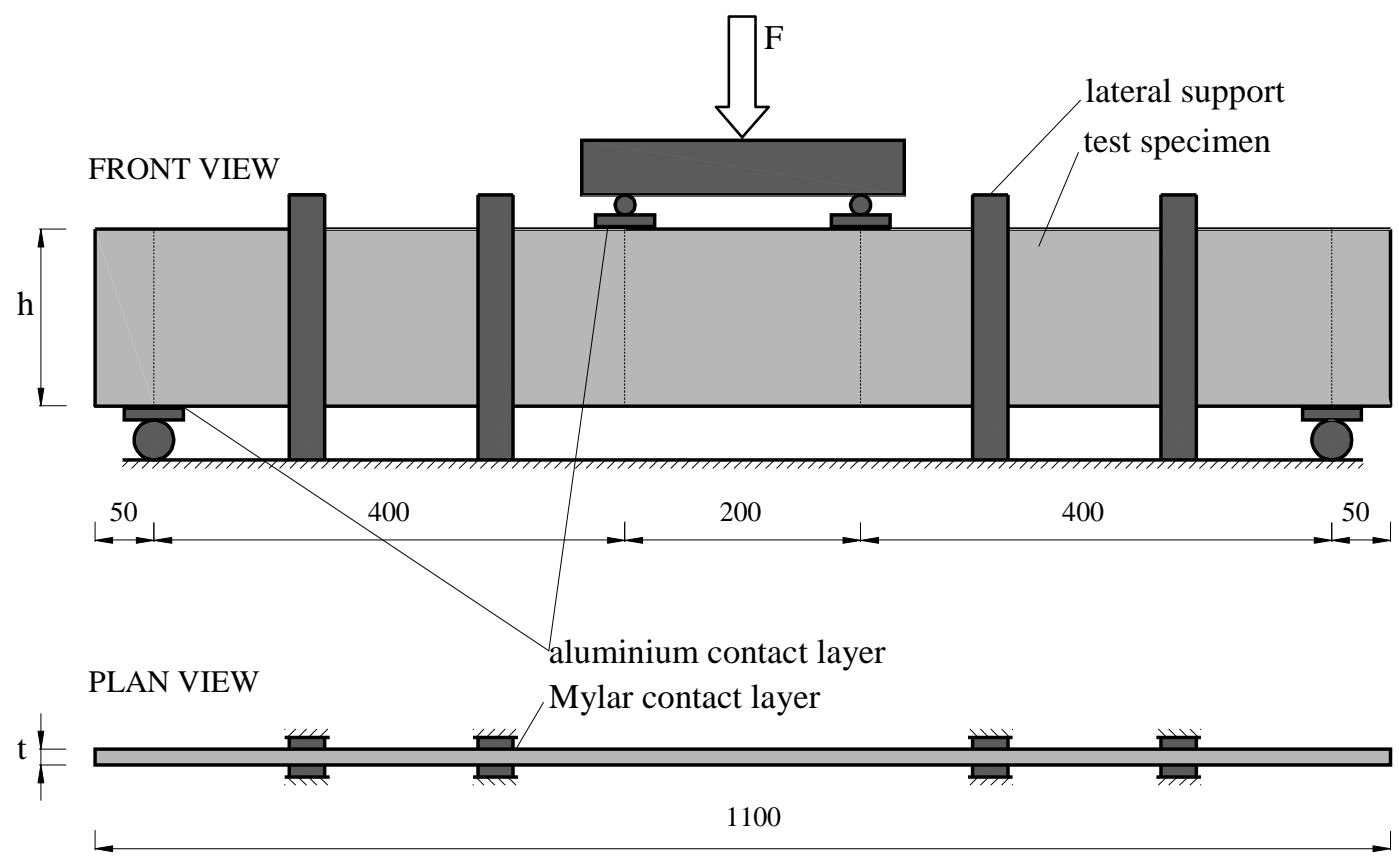

Fig. 5. Schematic overview of four-points bending test setup for in-plane bending

The data acquired consisted of the load (F), obtained by a load cell, and the vertical displacements (w) of the upper rim at mid span relatively to the supports, obtained by linear variable differential transducers (LVDT). The mean results of the ultimate loads $\left(\mathrm{F}_{\mathrm{u}}\right)$ and relative displacements $\left(\mathrm{w}_{\mathrm{u}}\right)$ are presented in Table 4.

\section{Discussion}

\subsection{Interlayer}

As was illustrated in Fig. 4, the uniaxial tensile tests on SGP samples revealed an elastoplastic behaviour which is dependent on the loading speed: higher loading speeds correspond to higher yielding stresses and more pronounced elongations during yielding. However, the loading speed did not significantly influence the failure strength, of which the obtained values correspond well to the material data provided by the manufacturer (Table 1). With the exception of the tests performed at the highest loading 
speed, the average elongation at failure (approximately $350 \%$ ) was a bit lower than expected (400\%, see Table 1). Initial yielding occurred at stress levels between 21 $\mathrm{N} / \mathrm{mm}^{2}$ and $25 \mathrm{~N} / \mathrm{mm}^{2}$ and corresponded to clearly visible necking of the sample's cross-section, which was further extended along the length of the sample as the strain increased (this corresponds to the horizontal parts of the curves in Fig. 4).

\subsection{Stage I}

Stage I corresponds to the unbroken state. The specimens with a height of $120 \mathrm{~mm}$ and $150 \mathrm{~mm}$ were loaded in the test setup described above. As depicted in Fig. 6, the measured deflections increased almost linearly with increasing load (F) until brittle fracture occurred in one of the glass sheets.

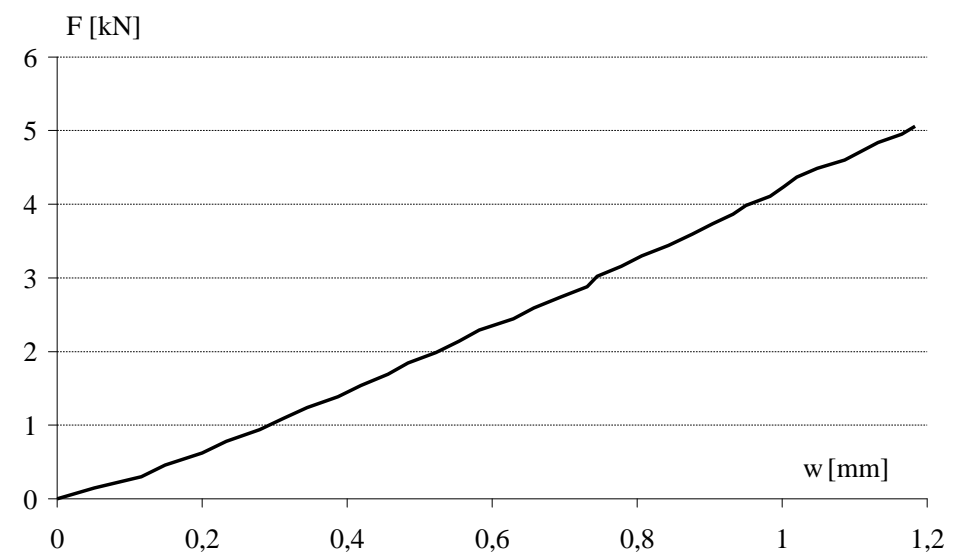

Fig. 6. Typical load (F) - deflection (w) curve in stage I (sample 120_2)

Subsequently, fracture of one glass sheet, depicted in (Fig. 7 (b)), was for most cases immediately followed by fracture of the other in the same section, as illustrated in (Fig. 7 (c)). This could be easily understood: as soon as the first fracture appeared, the load was transferred to the remaining sheet, which consequently became overloaded and broke. Due to this chain reaction, stage I was immediately followed by stage III. 
However, glass fracture did not always appear in the zone of maximal bending moments, but in the area where high stress concentration factors occurred because tensile stresses coincided with randomly distributed surface flaws. These flaws are well known for glass, and were mainly the result of mechanical edge treatments (polishing in this case). Consequently, for this stage the glass tensile strength was the determining factor, depending on manufacturing process and loading history.

(a)

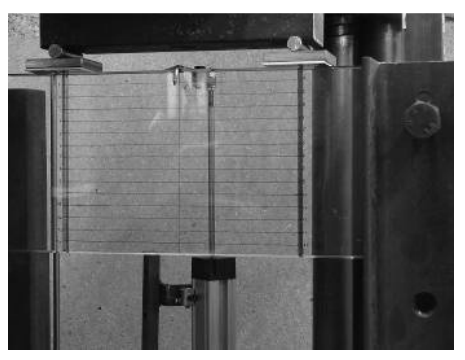

(b)

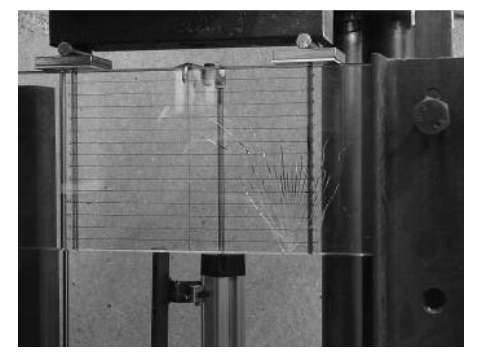

(c)

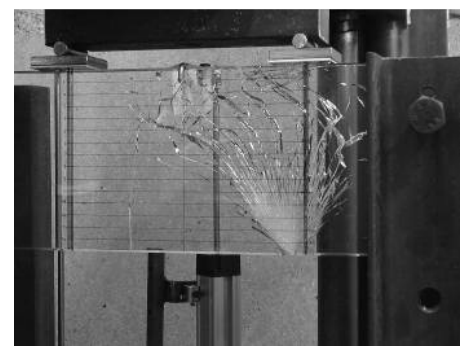

Fig. 7. Example of fracture sequence (sample 150_5): (a) Unbroken state; (b) Fracture of first glass sheet; (c) Immediate fracture of the second glass sheet (chain reaction)

In the design is generally assumed that the loads are carried by the glass sheets and the interlayer material could be neglected. The test results confirmed that this is an acceptable assumption.

However, the measured deflection was larger than the calculated value due to different reasons. One possible reason may be unequal load transfer to both glass sheets, caused by laminating tolerances, which allow a limited difference in height of both sheets, as illustrated in Fig. 8. 
(a)

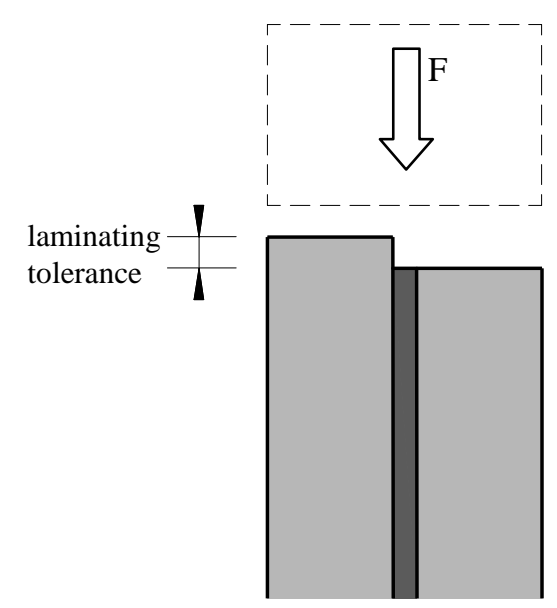

(b)

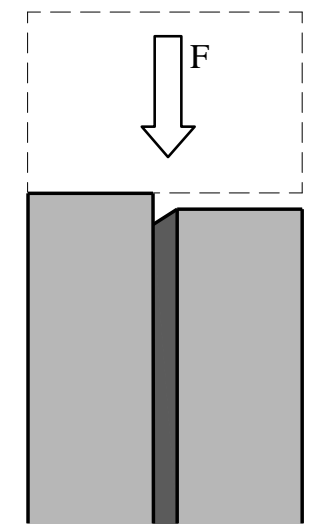

(c)

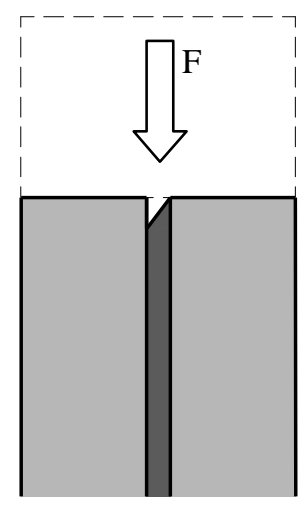

Fig. 8. Principle of unequal load transfer to both glass sheets due to laminating tolerances: (a) unloaded situation; (b) intermediate situation with load transfer through interlayer; (c) final situation

\subsection{Stage II}

Stage II applies when only one of the glass sheets is broken. In general, due to the chain reaction, this stage is absent when an unbroken beam is loaded. However, stage II is more likely to happen due to different causes, such as a hard body impact.

Consequently, this stage is also important for the residual strength and structural safety of the beam. To investigate this stage, a single crack at mid span was made in one glass sheet of each of the $200 \mathrm{~mm}$ high beams prior to the tests.

Again, a linear load-deflection relationship was observed until brittle fracture occured. Crack initiations did always occur in the centre of the beam span, corresponding to the location where the initial single crack in the other glass sheet had been made: the initial weakening of the specimens seemed to be significant enough to determine the position of fracture. 
The corresponding failure stress level in this stage was approximately $60 \%$ of that expected in stage I. In other words, the failure stress level was approximately $20 \%$ higher than the expected stress level for one glass sheet. Consequently, the SGP interlayer seemed to be able to transfer (at least partially) the compressive stresses that appeared between both pieces of the originally broken glas sheet, increasing the residual resistance of the damaged laminate. Again, the measured deflections were slightly underestimated by elastic theory.

\subsection{Stage III}

Stage III, studied for all test specimens, is very complex and ambiguous due to the large variety of crack origins, crack patterns and local delamination effects. After breakage of the second glass sheet the load decreased to a relatively low level (typically between 2 $\mathrm{kN}$ and $3 \mathrm{kN}$ ) before the broken glass pieces made contact and started to build up compressive stresses again. Subsequently, the load slightly increased again and after reaching a (sometimes barely noticeable) maximum, it decreased significantly (to less then $0.3 \mathrm{kN}$ ).

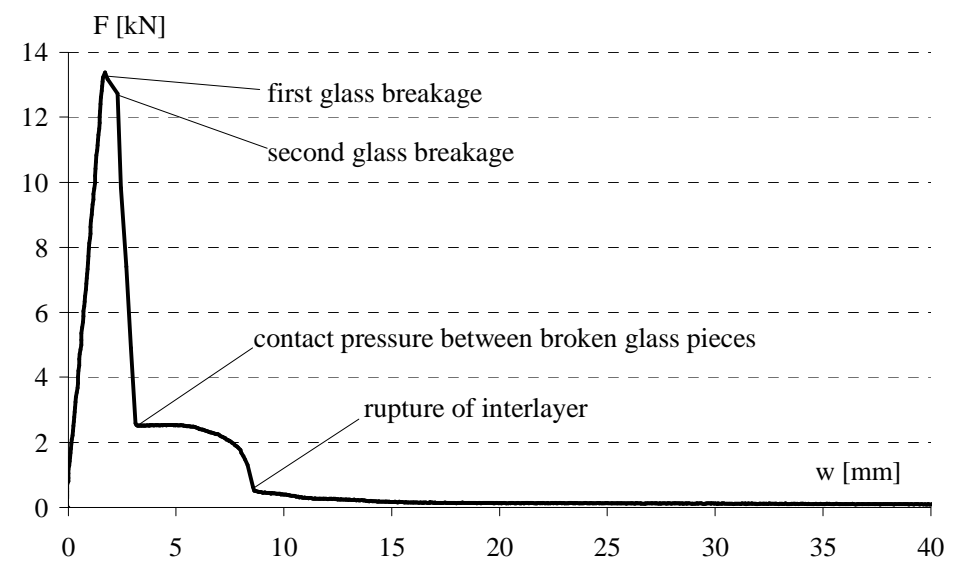

Fig. 9. Typical load (F) - deflection (w) curve in stage III (sample 150_4) 
Finally, an A-shaped gap appeared at the bottom where the SGP was fissured and large deflections were measured, as illustrated in Fig. 10. This was the case for the specimens with a height of $150 \mathrm{~mm}$ and $200 \mathrm{~mm}$. However, when testing the $120 \mathrm{~mm}$ high beams, the opening immediately appeared after breakage of the second sheet. Again, low load levels caused large deflections. As deformations increased, all beams finally failed due to tearing of the entire foil. As a result of the high adhesion of SGP to glass, local delamination around the crack origin was limited (Fig. 11) and the interlayer endured a large local deformation leading to fissuring. Consequently, the residual strength was lower than expected.

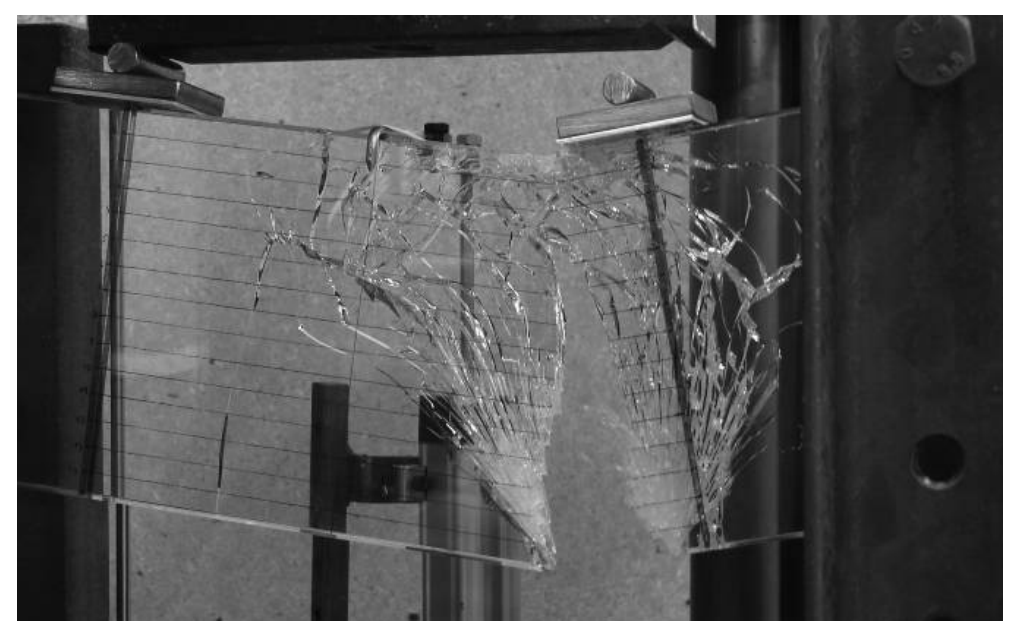

Fig. 10. Example of fissured SGP (specimen 150_5) 


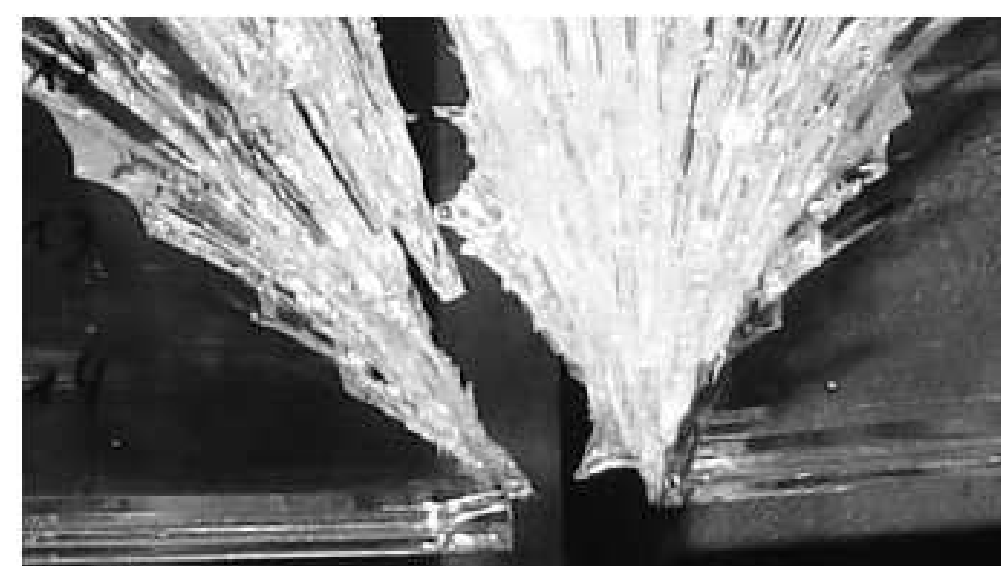

Fig. 11. Example of teared SGP and typically limited local delamination at crack origin

\subsection{Comparison between glass/SGP and glass/PVB beams}

\subsubsection{Role of the interlayer}

The glass breakage chain reaction observed here for glass/SGP beams is very similar to what has been observed by other authors studying glass/PVB beams [10]. Consequently, the failure load depends mainly on the beam edges failure strength and not on the interlayer used. However, this situation would change if lateral buckling were possible, because that would involve bending along the weak axis and consequent shear deformations of the interlayer [15] [16], illustrated in Fig. 1 c).

For example, Belis [16] observed that the average buckling load at room temperature of laminates with SGP is significantly larger than for those with PVB.

However, when subjected to in-plane bending (buckling prevented), the post-breakage residual resistance is relatively poor for both interlayers, as demonstrated above.

\subsubsection{Failure mechanisms}

On the other hand, the failure mechanisms ruling stage III differ greatly for beams with PVB and SGP interlayers. 
In contradiction to what was observed above for glass/SGP beams, glass/PVB beams showed a significant local delamination in the tensile zone near the crack origin, as depicted in Fig. 12. Consequently, PVB interlayers could develop large stretching zones, followed by large system deformations. Finally, this turned the static system into a mechanism, causing its collapse.

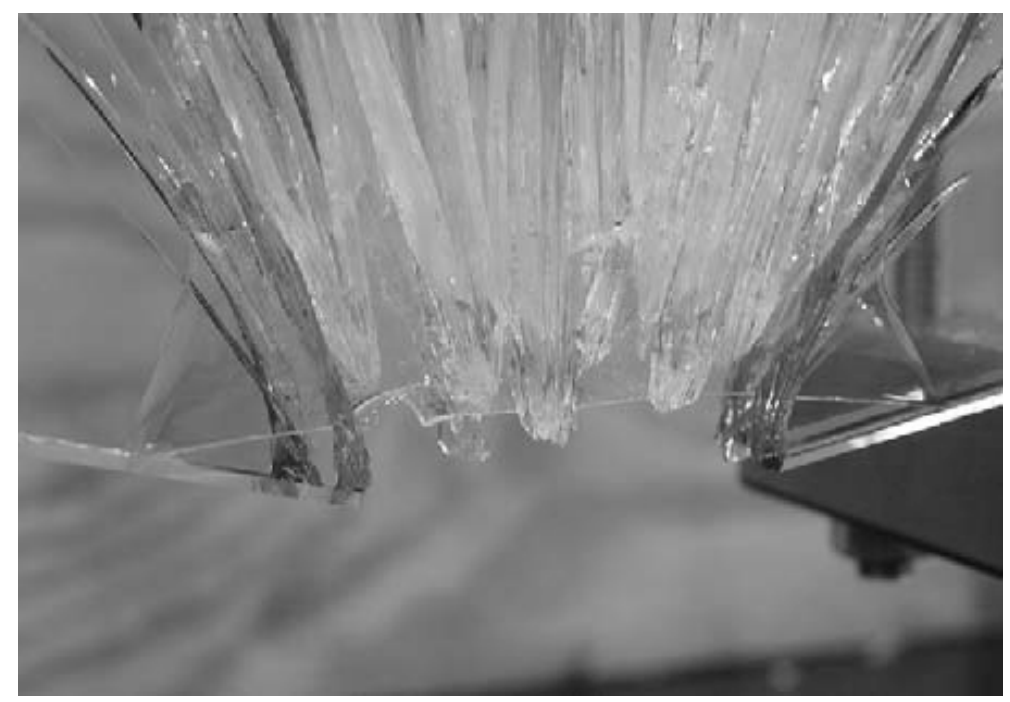

Fig. 12. Example of stretched PVB and typically large local delamination at crack origin [16]

As demonstrated above, this is contrasting to SGP failure mechanisms, in which very little local delamination, frequent rupture of the interlayer and collapse due to loss of structural integrity were observed.

\section{Summary and conclusions}

Different series of uniaxial tensile tests on SGP samples and in-plane four-points bending tests on annealed glass/SGP beams have been executed to evaluate their failure mechanisms and post-breakage mechanical behaviour at room temperature. The main results of this investigation are summarised below: 
1. Uniaxial tensile tests on small SGP samples revealed an elastic-plastic material behaviour with large elongations at failure (typically 350\%) and failure strengths above $32 \mathrm{~N} / \mathrm{mm}^{2}$.

2. The obtained load-deflection curves in stage I (the unbroken state) were almost linear, as was expected. In most tests, breakage of one glass sheet was immediately followed by breakage of the other and both crack initiations were located at the same position. Consequently, stage II (one glass sheet broken) did not appear and stage I was immediately followed by stage III (both glass sheets broken).

3. Stage II was investigated on glass/SGP beams of which one glass sheet was broken by a single crack at mid span prior to testing. The observed failure load of a partially broken laminate with one intact glass sheet was typically about $20 \%$ higher than what would be expected for the unbroken glass sheet only, pointing out the importance of the residual resistance of the originally broken glass panel. This could be explained by the compressive stresses between the originally broken glass pieces, which could develop only due to the good shear stress transfer of the SGP.

4. In stage III, studied for all test specimens, the residual load-bearing capacity was very limited and far below the initial glass strength..

5. Surprisingly, complete collapse of the laminated beams was always caused by tearing of the SGP at relatively low loading levels. This had not been expected, because the uniaxial tensile tests had shown a relatively high interlayer strength and large elongations at failure. However, the poor resistance could be explained by the very good adhesion of SGP to glass, which prevented local delaminations that would be necessary to develop larger deformations and to keep tensile stresses in the interlayer below the ultimate SGP tensile strength. 
6. Consequently, it is recommended to take into account the delamination behaviour when evaluating interlayers with respect to (post-)failure mechanisms. To do so, alternative testing methods, such as Through-Crack-Tensile tests, should be used rather than traditional uniaxial tensile tests.

7. Compared to PVB, the use of a "stiff" interlayer such as SGP seemed not to improve the in-plane bending resistance of laminated glass beams, as that is only depending on the glass strength. In addition, the post-failure safety in the examined cases is rather negligible for both interlayer types. However, failure mechanisms are different for both materials: contrary to the examined SGP beams, glass/PVB beams do show important local delaminations and consequent large interlayer stretching. Consequently, hinges will appear very quickly and the static system will become a mechanism. Therefore, it is recommended to use proper boundary conditions (structural sealants, mechanical fixings...) or additional safety concepts (reinforcement, ...) to improve the overall post-failure behaviour of the whole system.

8. Finally, it should be emphasised that the residual load-bearing capacity of glass/SGP laminated beams might be significantly better in case heat-strengthened or fully tempered glass is used. The main reason for this is the much denser crack pattern, which will allow the interlayer to deform at many different locations at the same time, keeping local stresses below the failure level. In addition, it should be clear that also a different serviceability temperature will influence the properties of SGP and consequently, also those of laminated beams composed with it. 


\section{Acknowledgements}

This work was supported by the Fund for Scientific Research-Flanders (FWOVlaanderen, Grant nr. 3G018407). Additionally, the authors gratefully wish to acknowledge the support of Lerobel (Groep Leroi, Belgium) and DuPont de Nemours Belgium.

\section{References}

[1] Hooper J. On the bending of architectural laminated glass. Int J Mech Sci 1973: 15; $309-25$.

[2] Behr R, Minor J, Norville H. Structural Behavior of Architectural Laminated Glass. J Struct Eng ASCE 1993; 119: 202-20.

[3] Bennison SJ, Jagota A, Smith CA. Fracture of glass/poly(vinyl butyral) (Butacite (R)) laminates in biaxial flexure. J Am Ceram Soc 1999; 82: 1761-10.

[4] Seshadri M, Bennison SJ, Jagota A, Saigal S. Mechanical response of cracked laminated plates. Acta Mater 2002; 50: 4477-14.

[5] Kott A. Zum Trag- und Resttragverhalten von Verbundsicherheitsglas. Zürich: Eidgenössische Technische Hochschule Zürich; 2006.

[6] Bucak O, Meissner M. Trag- und Resttragfähigkeitsuntersuchungen an Verbundglas mit den Zwisschenlage "SentryGlas ${ }^{\circledR}$ Plus" - Abschlussbericht. München: AIF Fachhochschule München; 2005.

[7] Depauw J. Bezwijkgedrag van glas/ionoplast laminaten bij kamertemperatuur. Ghent: Ghent University; 2007. not published. 
[8] Belis J, Delincé D, Depauw J, Callewaert D, Van Impe R. Plastic deformation of polymer interlayers during post-breakage behaviour of laminated glass - Partim 1: Analytical approach. Mod Phys Lett B. Accepted manuscript.

[9] Delincé D, Depauw J, Callewaert D, Vanlaere W, Belis J. Plastic deformation of polymer interlayers during post-breakage behaviour of laminated glass - Partim 2: Experimental validation. Mod Phys Lett B. Accepted manuscript.

[10] Hess R. Glasträger. Zürich: vdf Hochschulverlag AG an der ETH Zürich; 2000.

[11] DIN EN ISO 527-2. Plastics - Determination of tensile properties - Part 2: Test conditions for moulding and extrusion plastics. DIN: 1996.

[12] DuPont de Nemours. SentryGlas ${ }^{\circledR}$ Plus Elastic Properties (SGP5000). DuPont; 2008.

[13] DIN EN ISO 527-1. Plastics - Determination of tensile properties - Part 1: General principle. DIN: 1996.

[14] EN 1288-3. Glass in building - determination of the bending strength of glass Part 3: Test with specimen supported at two points (four point bending), 2000.

[15] Luible A. Stabilität von Tragelementen aus Glas. Lausanne: Ecole Polytechnique Fédérale de Lausanne; 2004.

[16] Belis, J. Kipsterkte van monolithische en gelamineerde glazen liggers. Gent: Universiteit Gent; 2005.

[17] DuPont de Nemours. SentryGlas® Plus Elastic Properties (SGP5000). DuPont; 2008.

[18] DuPont de Nemours. DuPont ${ }^{\mathrm{TM}}$ SentryGlas ${ }^{\circledR}$ Plus ionoplast interlayer Doc. Ref. SGP030718_1. Worldwide: DuPont; 2003. 


\section{Figure Captions}

Fig. 1. Basic loading situations for laminated glass: (a) as a plate; (b) as a beam; and (cd) corresponding longitudinal cross-sections during loading

Fig. 2. Three stages in the failure process of a laminated plate composed of two glass sheets and one interlayer (in the example shown, the upper sheet broke first, e.g. due to a hard body impact)

Fig. 3. Basic shape and main sizes of SGP samples used for uniaxial tensile tests [mm] (for more details, see EN ISO 572-2 [11])

Fig. 4. Stress-strain curves of SGP 2000 samples subjected to uniaxial tensile tests at room temperature

Fig. 5. Schematic overview of four-points bending test setup for in-plane bending Fig. 7. Example of fracture sequence (sample 150_5

Fig. 8. Principle of unequal load transfer to both glass sheets due to laminating tolerances: (a) unloaded situation; (b) intermediate situation with load transfer through interlayer; (c) final situation

Fig. 10. Example of fissured SGP (specimen 150_5)

Fig. 11. Example of teared SGP and typically limited local delamination at crack origin Fig. 12. Example of stretched PVB and typically large local delamination at crack origin [16] 


\section{Tables}

Table 1

Material properties of PVB [5] and SGP [18]

\begin{tabular}{lllllll}
$\begin{array}{l}\text { Interlayer } \\
\text { material }\end{array}$ & $\begin{array}{l}\text { Shear } \\
\text { modulus } \\
{\left[\mathbf{N} / \mathbf{m m}^{2}\right]}\end{array}$ & $\begin{array}{l}\text { Poisson's } \\
\text { ratio }\end{array}$ & $\begin{array}{l}\text { Tensile } \\
{[-]}\end{array}$ & $\begin{array}{l}\text { Elongation at } \\
{\left[\mathbf{N} / \mathbf{m m}^{2}\right]}\end{array}$ & $\begin{array}{l}\text { Coefficient of } \\
\text { failure } \\
{[\%]}\end{array}$ & $\begin{array}{l}\text { Density } \\
\text { thermal } \\
{\left[\mathbf{k g} / \mathbf{m}^{3}\right]}\end{array}$ \\
\hline \hline PVB* & $0-70$ & $\approx 0.5$ & $\geq 23$ & 280 & $2.2 \cdot 10^{-4}$ & $1000-1070$ \\
SGP & 100 & $\approx 0.5$ & 34.5 & 400 & $10-15 \cdot 10^{-3}$ & 950 \\
\hline
\end{tabular}

* PVB values may change according to manufacturer. 
Table 2

Overview of test samples

\begin{tabular}{|c|c|c|c|c|c|}
\hline Name & $\begin{array}{l}\text { Mean height } \\
{[\mathrm{mm}]}\end{array}$ & $\begin{array}{l}\text { Glass } \\
\text { thickness a } \\
\text { (front plate) } \\
\text { [mm] }\end{array}$ & $\begin{array}{l}\text { Glass } \\
\text { thickness a } \\
\text { (back plate) } \\
\text { [mm] }\end{array}$ & $\begin{array}{l}\text { Mean } \\
\text { interlayer } \\
\text { thickness t } \\
{[\mathrm{mm}]}\end{array}$ & $\begin{array}{l}\text { Failure stages } \\
\text { studied } \\
{[-]}\end{array}$ \\
\hline $\begin{array}{l}120 \_1 \\
\end{array}$ & 120.78 & 5.95 & 5.97 & 1.71 & I and III \\
\hline $120 \_2$ & 120.79 & 5.97 & 5.94 & 1.70 & \\
\hline $120 \_3$ & 120.32 & 5.96 & 5.95 & 1.64 & \\
\hline $120 \_4$ & 120.29 & 5.95 & 5.97 & 1.61 & \\
\hline $120 \_5$ & 120.27 & 5.94 & 5.82 & 1.72 & \\
\hline $120 \_6$ & 120.30 & 5.96 & 5.8 & 1.76 & \\
\hline $120 \_7$ & 119.45 & 5.96 & 5.94 & 1.72 & \\
\hline $120 \_8$ & 119.30 & 5.95 & 5.94 & 1.74 & \\
\hline 150_1 & 149.94 & 5.95 & 5.95 & 1.72 & I and III \\
\hline $150 \_2$ & 149.97 & 5.93 & 5.95 & 1.75 & \\
\hline $150 \_3$ & 150.01 & 5.95 & 5.94 & 1.71 & \\
\hline $150 \_4$ & 150.02 & 5.94 & 5.96 & 1.73 & \\
\hline $150 \_5$ & 150.26 & 5.85 & 5.84 & 1.75 & \\
\hline $150 \_6$ & 150.21 & 5.89 & 5.9 & 1.64 & \\
\hline $150 \_7$ & 150.04 & 5.90 & 5.90 & 1.66 & \\
\hline $150 \_8$ & 149.91 & 5.84 & 5.82 & 1.78 & \\
\hline 200_1 & 199.79 & 5.97 & 5.98 & 1.66 & II and III \\
\hline $200 \_2$ & 199.76 & 5.95 & 5.96 & 1.71 & \\
\hline $200 \_3$ & 199.84 & 5.96 & 5.95 & 1.70 & \\
\hline $200 \_4$ & 199.74 & 5.95 & 5.95 & 1.68 & \\
\hline $200 \_5$ & 200.47 & 5.98 & 5.97 & 1.69 & \\
\hline $200 \_6$ & 200.55 & 5.98 & 5.97 & 1.69 & \\
\hline $200 \_7$ & 199.81 & 5.95 & 5.94 & 1.77 & \\
\hline $200 \_8$ & 199.88 & 5.96 & 5.94 & 1.76 & \\
\hline
\end{tabular}


Table 3

Overview of mean uniaxial tensile test results on standardised SGP 2000 samples at room temperature

\begin{tabular}{llllll}
$\begin{array}{l}\text { Loading } \\
\text { speed s } \\
{[\mathbf{m m} / \mathbf{m i n}]}\end{array}$ & $\begin{array}{l}\text { Number of } \\
\text { Specimens } \\
\text { tested }[-]\end{array}$ & $\begin{array}{l}\mathbf{f}_{\mathbf{y}}^{*} / \text { standard } \\
\mathbf{d e v i a t i o n} \\
{\left[\mathbf{N} / \mathbf{m m}^{2}\right]}\end{array}$ & $\begin{array}{l}\boldsymbol{\varepsilon}_{\mathbf{y}} / \text { standard } \\
\text { deviation } \\
{[\%]}\end{array}$ & $\begin{array}{l}\boldsymbol{\sigma}_{\mathbf{u}}^{*} / \text { standard } \\
\text { deviation } \\
{\left[\mathbf{N} / \mathbf{m m}^{2}\right]}\end{array}$ & $\begin{array}{l}\boldsymbol{\varepsilon}_{\mathbf{u}} / \text { standard } \\
\text { deviation } \\
{[\%]}\end{array}$ \\
\hline \hline 5 & 5 & $20.97 / 0.17$ & $7.37 / 0.18$ & $33.19 / 1.21$ & $339.43 / 10.61$ \\
10 & 5 & $21.86 / 0.33$ & $8.32 / 0.13$ & $34.32 / 1.04$ & $340.53 / 5.08$ \\
20 & 5 & $22.40 / 0.13$ & $8.48 / 0.17$ & $32.44 / 1.38$ & $331.25 / 10.97$ \\
50 & 5 & $23.79 / 0.17$ & $8.59 / 0.13$ & $33.10 / 0.98$ & $342.33 / 3.26$ \\
100 & 5 & $25.09 / 0.17$ & $8.65 / 0.36$ & $35.71 / 0.83$ & $386.56 / 6.38$ \\
\hline
\end{tabular}

* Stresses given are nominal stress values (load divided by initial cross-section) 
Table 4

Overview of mean values of in-plane four-points bending test results on glass/SGP laminates at room temperature

\begin{tabular}{|c|c|c|c|c|c|c|}
\hline $\begin{array}{l}\text { Specimen } \\
\text { height } \\
{[\mathrm{mm}]}\end{array}$ & $\begin{array}{l}\text { Mean } \\
\text { loading } \\
\text { speed } \mathrm{s} \\
{[\mathrm{mm} / \mathrm{min}]}\end{array}$ & $\begin{array}{l}\text { Number of } \\
\text { successful } \\
\text { tests } \\
{[-]}\end{array}$ & $\begin{array}{l}\mathrm{F}_{\mathrm{u}, \mathrm{I}} / \\
\text { standard } \\
\text { deviation } \\
{[\mathrm{N}]}\end{array}$ & $\begin{array}{l}\mathbf{F}_{\mathrm{u}, \mathrm{II}} / \\
\text { standard } \\
\text { deviation } \\
{[\mathrm{N}]}\end{array}$ & $\begin{array}{l}\mathrm{w}_{\mathrm{u}, \mathrm{I}} / \\
\text { standard } \\
\text { deviation } \\
{[\mathrm{mm}]}\end{array}$ & $\begin{array}{l}\mathbf{w}_{\mathrm{u}, \mathrm{II}} / \\
\text { standard } \\
\text { deviation } \\
{[\mathrm{mm}]}\end{array}$ \\
\hline 120 & 0.1 & 7 & $5467 / 298$ & - & $\begin{array}{l}1.226 / \\
0.080\end{array}$ & - \\
\hline 150 & 0.4 & 7 & $\begin{array}{l}11370 / \\
2194\end{array}$ & - & $\begin{array}{l}1.447 / \\
0.299\end{array}$ & - \\
\hline 200 & 0.1 & 6 & - & $\begin{array}{l}12148 \\
/ 1585\end{array}$ & - & $\begin{array}{l}1.298 / \\
0.149\end{array}$ \\
\hline
\end{tabular}

